\title{
The Influence of Tree Diversity on Natural Enemies-a Review of the "Enemies" Hypothesis in Forests
}

\author{
Michael Staab ${ }^{1}$ - Andreas Schuldt ${ }^{2}$ \\ Published online: 18 July 2020 \\ (C) The Author(s) 2020
}

\begin{abstract}
Purpose of Review Natural enemies are an important component for forest functioning. By consuming herbivores, they can be effective top-down regulators of potential pest species. Tree mixtures are generally expected to have larger predator and parasitoid populations compared to monocultures. This assumption is based on the "enemies" hypothesis, a classical ecological concept predicting a positive relationship between plant diversity (and complexity) and natural enemies, which, in turn, should increase top-down control in more diverse environments. However, the "enemies" hypothesis has mostly been tested and supported in relatively simple agricultural ecosystems. Until recently, research in forests was sparse. We summarize the upcoming knowledge-base for forests and identify forest characteristics likely shaping relationships between tree diversity, natural enemies (abundance, species richness, diversity), and top-down control. We further identify possible implications for mixed species forestry and key knowledge gaps.

Recent Findings Tree diversity (almost exclusively quantified as tree species richness) does not consistently increase enemy abundance, diversity, or result in herbivore control. Tests of the "enemies" hypothesis are largely based on aboveground natural enemies (mainly generalists) and have highly variable outcomes across taxa and study systems, sometimes even finding a decrease in predator diversity with increasing tree diversity. Recurrent effects of tree species identity and composition indicate that a closer focus on tree functional and phylogenetic diversity might help to foster a mechanistic understanding of the specific circumstances under which tree diversity can promote top-down control.

Summary Our review suggests that the "enemies" hypothesis may not unambiguously apply to forests. With trees as structurally complex organisms, even low-diversity forests can maintain a high degree of habitat heterogeneity and may provide niches for many predator and parasitoid species, possibly blurring correlations between tree and natural enemy diversity. Several further factors, such as latitude, identity effects, intraguild predation, or functional and phylogenetic components of biodiversity, may confound the predictions of the "enemies" hypothesis. We identify topics needing more research to fully understand under which conditions tree diversity increases natural enemy diversity and top-down control—knowledge that will be crucial for forest management.
\end{abstract}

Keywords Arthropod $\cdot$ Complexity $\cdot$ Herbivore $\cdot$ Mixed species forestry $\cdot$ Pest control $\cdot$ Predation $\cdot$ Top-down effects

This article is part of the Topical Collection on Forest Entomology

Michael Staab

michael.staab@nature.uni-freiburg.de

Andreas Schuldt

andreas.schuldt@forst.uni-goettingen.de

1 Nature Conservation and Landscape Ecology, University of Freiburg, Tennenbacher Straße 4, 79106 Freiburg, Germany

2 Forest Nature Conservation, Georg-August-University Göttingen, Büsgenweg 3, 37077 Göttingen, Germany

\section{Introduction}

In the light of recent declines in forest biodiversity [1], policy makers and forest managers are increasingly adopting more ecologically sustainable management strategies that can help to promote biodiversity and its functional benefits $[2,3]$. In terms of biodiversity and forest functioning, natural enemies (i.e., including vertebrate and invertebrate predators and invertebrate parasitoids) play a key role $[4,5]$. By consuming herbivores, these organisms can be effective top-down regulators of potential pest species [6], which becomes particularly relevant considering predicted increases of future biotic 
disturbances [7]. The strength of top-down effects can depend on natural enemy diversity [8•], and promoting this diversity might therefore contribute to natural biocontrol [5, 9-11].

The diversity of natural enemies in a forest stand, in turn, depends on environmental conditions and structural attributes that modify niche space and resource availability $[12,13,14 \cdot]$. Thus, developing strategies for sustainable and environmentally friendly forest management should consider sustaining predators and parasitoids. Tree species mixtures are generally expected to increase the resilience of forest stands compared to monocultures, for example, in relation to climate change and associated abiotic and biotic disturbances such as insect herbivore outbreaks $[15,16]$. At the same time, tree species richness might promote the biodiversity of associated heterotrophic organisms (e.g., [13, 17•]), which in turn can have important consequences for ecosystem functioning $[18,19]$. For natural enemies and their diversity, these relationships are explicitly addressed by the "enemies" hypothesis (Box 1, Fig. 1). First summarized in the influential paper by Root [20] and critically elaborated on over time (e.g., [21, 22]), the "enemies" hypothesis posits that more diverse habitats stabilize predator and parasitoid population dynamics and promote their abundance and diversity because of a higher diversity and stability of prey and other resources. This, in turn, should lead to higher predation pressure, parasitism, and more effective control of herbivores (Box 1).

Box 1 Theoretical foundations and predictions of the "enemies" hypothesis for forests

The "enemies" hypothesis was originally postulated by Root in 1973 [20], who had studied arthropod communities on Brassica oleracea planted in monoculture and interspersed with diverse meadow vegetation. According to the hypothesis, predators (and other natural enemies such as parasitoids) are more effective at controlling herbivore populations in diverse than in simple vegetation (Fig. 1). Root's main explanation was via population stability (for generalized predators/parasitoids) because in diverse habitats, natural enemies can use a wide variety of prey and because prey populations are temporarily more stable. For specialist enemies, he predicted that populations would fluctuate less "because the refuge provided by a complex environment enables host species to escape widespread annihilation" [20].

The intuitive predictions of the "enemies" hypothesis are often supported in agricultural ecosystems (e.g., [21, 23, 24]). However, it might be that in communities with long-lived plant individuals, such as forests, plant diversity-facilitated top-down control might differ from annual communities where consumer assemblages need to reassemble anew each year. Mechanistically, species-rich forest stands are predicted to increase predator abundance and diversity, which subsequently increases predation pressure towards herbivores. Alternatively, predators might also be more active or efficient when tree diversity is high, or intraguild predation might be lower in more diverse habitats [25]. Tree diversity could work via increased habitat heterogeneity or by stabilizing resources (prey, shelter, alternative food sources such as nectar), or by forcing herbivores to move more between different plants and thus increasing predation risk [26].

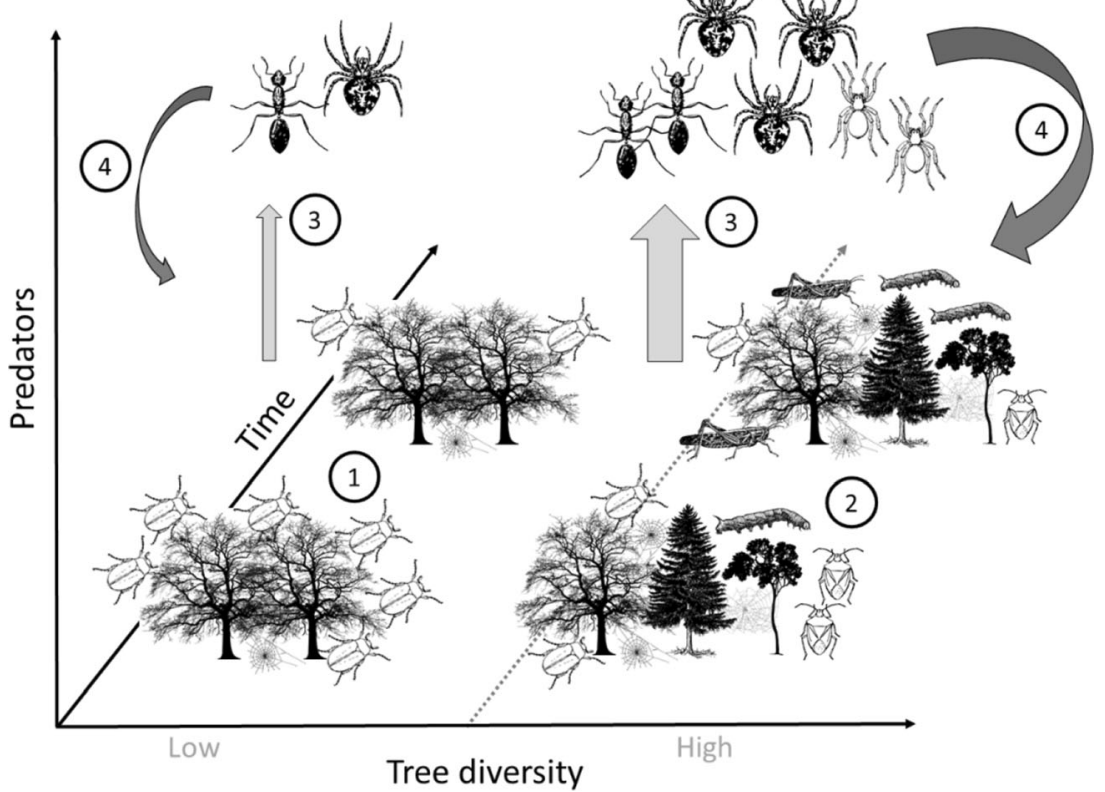

Fig. 1 Schematic representation of the pathways involved in the predictions of the "enemies" hypothesis applied to forests. (1) Low plant diversity (here: tree species richness) creates uniform habitats and low resource availability (here: specialized herbivore populations). (2) High plant diversity provides a higher diversity of resources (both in terms of alternative prey and other resources, here: structures to attach spider web types). (3) These patterns lead to stronger promotion of predators (in terms of abundance, diversity, or population stability) in more diverse plant communities, (4) which in turn results in stronger top-down effects on herbivores. Clip art from https://pixabay.com is licensed for use in the public domain without copyright (Creative Commons Zero 1.0) 
The "enemies" hypothesis has been tested predominantly in agroecosystems and grasslands so far, for which reviews, meta-analyses and large-scale experiments show that its predictions hold in many cases (e.g., [21-23, 27]). However, whether these findings can be transferred to forests is an ongoing matter of debate. Consisting of long-lived and structurally complex organisms with a high standing biomass (i.e., trees), forests differ substantially in their structural characteristics and temporal dynamics from simplified agroecosystems and grasslands $[17 \bullet, 28]$. Explicit and properly designed tests of the "enemies" hypothesis in forests are much less common [29] and almost exclusively restricted to aboveground organisms. For example, meta-analyses from agroforestry systems, which are structurally related to forests, indicated the important role of predators (particularly birds) in ecosystems with trees $[30,31]$, however without considering effects of tree diversity. Moreover, the high variability in management and climatic conditions under which forests grow complicate generalizations of the available data (e.g., [32]). For example, early analyses in boreal forests did not find consistent effects of tree species richness on the abundance of predatory arthropods [33]. While a few subsequent studies of other forest ecosystems found support for the predictions of the "enemies" hypothesis (e.g., $[34,35]$ ), many others were unable to detect positive relationships (e.g., [36]). In some cases, tree species composition rather than tree species richness influenced predator communities (e.g., [33, 37]). Meanwhile, over the last decade, more studies, notably from an increasing number of tree diversity experiments [29], have tested the "enemies" hypothesis in forest ecosystems with a focus on aboveground organisms. This newly accumulated literature allows for a synthesis and an evaluation of the conditions and possible limitations under which the "enemies" hypothesis applies in forest ecosystems (Fig. 1). Furthermore, it is now possible to summarize how concordance with, and potential deviations from, the predictions of this hypothesis can inform forest management. The aims of our review are therefore to (1) provide a summary of current knowledge, with a focus on studies published over the last 5 years; (2) determine the characteristics of forest communities that might shape the relationship between tree diversity, predator diversity, and top-down control; (3) discuss the enemies hypothesis with respect to mixed species forestry and identify knowledge gaps and promising topics for future research.

\section{Recent Developments on the "Enemies" Hypothesis in Forests}

For our review, we focused primarily on research published within the last 5 years, but additionally considered earlier studies when there was a lack of current work on specific aspects. Our literature search was based on queries of the ISI Web of Knowledge using "predator" OR "enemy" OR "parasitoid" AND "forest" OR "tree" AND "diversity" as search terms, as well as checking all papers citing Root's [20] original reference to the "enemies" hypothesis. We include experimental studies from tree diversity experiments [29] and observational studies from natural forests. While diversity experiments allow for causal inference, we opted for including observational studies. Otherwise, we would considerably restrict the literature available for synthesis, which would only refer to very young forests, as most tree diversity experiments where established rather recently.

In the following, we summarize main developments based on exemplary studies, separated by major taxa (spiders, ants, beetles, parasitoids, birds, and bats). The separate treatment per taxon reflects the prevalence of studies focusing on individual taxonomic groups of enemies, rather than addressing the multi-taxon community of natural enemies that might contribute to top-down control in forests. This is a sensible approach when considering that some early studies (e.g., [33]) found positive correlations between tree diversity and the abundance of individual predator taxa. As taxon-specific studies may also form the bulk of "enemies" hypothesis tests in the nearer future, the separation by taxa in the next section provides specific summaries on which further work can build. Nevertheless, different groups of predators can interact in multiple ways $[38,39,40 \bullet \cdot]$ and net top-down control may be a result of these interactions. We therefore also summarize results for recent multi-taxon studies.

We note that almost all taxon-specific research focused on rather generalist natural enemies. Explicit tests of the "enemies" hypothesis for more specialized predator taxa such as lacewings, ladybird beetles or hoverflies are lacking (but see [41]) and thus not part of this review.

\section{Spiders}

Spiders are among the dominant invertebrate predators in terrestrial ecosystems, including forests. As generalist predators inhabiting all strata from the soil to the canopy, spiders play an important role in forest food webs [6]. Recent studies on spider communities and their relationship with tree diversity are available from temperate as well as (sub)tropical forests. Comparisons of monocultures with two-species mixtures in Ireland found no significant effect of tree species richness on spider species richness [42, 43]. Spider abundances varied among stand types, but were influenced by tree species identity rather than tree species richness. A very similar pattern was found in a temperate tree diversity experiment [37], concurring with the strong tree species-specific patterns for spider abundance reported earlier [33]. In contrast, species richness and abundance of web-building spiders on mahogany (Swietenia macrophylla) was higher in mixtures of tropical tree plantations than in mahogany monocultures [44]. Although not explicitly tested in that study, higher 
microhabitat or prey availability was speculated as drivers of these patterns [44] (and very likely apply across enemy taxa, see below). Interestingly, an earlier study on the same experimental study plots focusing primarily on freely hunting spiders (salticids) showed that the abundance of these spiders was not significantly related to tree species richness [45].

All of these studies tested relatively short gradients of tree species richness, which may increase the likelihood of effects of tree species identity [46] because the relative contribution of each tree species to the species pool is larger at low tree species richness. Using managed forests with a larger pool of altogether 15 tree species, and study plots from monospecific stands to mixtures with 3-5 tree species, an observational study in managed forests [13] found that spider species richness and abundance were positively related to tree species richness across Europe. In subtropical Chinese forests characterized by higher levels of tree and spider species richness, spider abundance and species richness were not positively related to tree species richness - neither in natural forests (negative relationship; [36]) nor in a large-scale tree diversity experiment (no relationship; [47]). However, the functional diversity of the spider assemblages in the natural forest sites increased with tree species richness [48], highlighting that different components of predator diversity can show deviating patterns. The same might apply for the quantification of tree diversity. The tree identity effects observed in several of the studies summarized above could be an indicator that tree functional diversity would capture tree diversity effects on predators in a better way (see also [17•], but see [13]). Nevertheless, experimental studies on the effects of tree functional diversity on predators are still scarce. For the natural subtropical forest discussed above, however, the abundance of spiders was unrelated to tree phylogenetic diversity [49], a potential proxy of functional diversity $[50,51]$.

\section{Predatory Ants}

Similar to spiders, ants are ubiquitous arthropods in forests. While ants are traditionally seen as predators, not all ants are strictly predatory [52]. Many species that forage on trees acquire part of their energy from plant-based sources by collecting nectar [53], by taking sap from herbivore-induced wounds [54], and especially by tending Hemiptera for honeydew [55]. The latter interaction is often referred to as trophobiosis, which is a tri-trophic interaction between plants, sap-sucking Hemiptera, and ants. While Hemiptera are herbivores consuming plant sap, ants frequently establish a foodfor-protection mutualism, in which they protect the sapsuckers against natural enemies in reward for honeydew. This trophic flexibility in a key predator taxon complicates the inference regarding the "enemies" hypothesis, especially when ants facilitate sap-sucking herbivores whose prevalence can increase with tree diversity $[54,56,57]$, which might negate their net effect on herbivore control (sensu [58]).
Nevertheless, even those ants preferably foraging for plantbased resources affect other arthropods and can reduce the densities of herbivores [59]. Likewise, ants may interfere with other predators, particularly spiders $[39,60]$.

A recent observational study found positive effects of tree species richness on predatory, but not omnivore ant species richness in the abovementioned subtropical forests where spider species richness declined with increasing tree species richness [35]. Similarly, the species richness and occurrence of Hemipteratending ants [57] increased with tree species richness in a subtropical tree diversity experiment spanning a gradient in tree species richness from monocultures to 24 -species mixtures. A study on leaf litter ants in the same experiment revealed positive correlations between tree species richness and ant abundance, species richness and phylogenetic diversity [61 •*], indicating that the "enemies" hypothesis can apply to forest-floor organisms that do not directly interact with trees. A positive effect of tree species richness on ant species richness was also observed in species poor, managed forests in temperate Europe, although effects were weaker than those of tree species identity [62].

In contrast, litter ant abundance and species richness in a young Australian tree diversity experiment were unrelated to woody plant species richness [63]. Likewise, ant abundance did not differ in an experiment comparing mahogany monocultures to mixtures of four tree species [56]. Fewer studies have directly tested how tree diversity affects the potential top-down effects of ants on other organisms. For example, ants were largely responsible for increased predation rates on artificial caterpillars with increasing tree diversity in natural tropical forests [64]. Finally, an experiment with saplings of three pine species observed an increase in ant abundance with increasing pine tree species richness and a concomitant decrease in the abundance of other predators and non-aphid herbivores - a pattern that was absent on trees where ants had been experimentally excluded [65].

\section{Predatory Beetles}

Of the predatory beetle families that are abundant in forests, ground beetles (Carabidae) are by far the most-studied taxon. Although not all ground beetle species are predators, assemblages in forests are frequently dominated by predatory species [66]. As for other predatory arthropods, tests of the "enemies" hypothesis have shown variable outcomes. In 150 managed forest stands across Germany, ground beetle species richness and the richness and abundance of rove beetles were positively related to overall vascular plant diversity [67]. In northeast China, positive correlations between woody plant and ground beetle species richness occurred only in mature, but not in younger secondary forests [68], highlighting that forest age and subsequent successional changes in structural properties can moderate the "enemies" hypothesis. In contrast, abundance and species richness of ground and rove beetles did 
not differ consistently between monocultures and two-species mixtures in plantation forests in Ireland ([42, 43], see also [69] for similar results). Likewise, a lack of tree species richness effects on ground beetle species richness was observed in a tree diversity experiment in France, but the abundance of ground beetles was positively related to overall vegetation diversity in this study [70]. Predatory beetles (unspecified families) in the litter layer of managed temperate forests were not influenced by tree diversity, although the effect of tree diversity was indirectly inferred via effects on herbivore diversity [71].

A range of studies have analyzed the response of canopy beetles to changes in tree diversity, for example, in mature forests in Germany, where the species richness of predatory beetles in tree canopies significantly increased with tree species richness [72]. However, most canopy studies did not distinguish between predatory and non-predatory species (e.g., [73]). The general dearth of explicit tests of the "enemies" hypothesis for canopies (apart from the canopies of young trees in experimental plantations) exemplifies that higher forest strata are still understudied [74].

\section{Parasitoids}

Several earlier observational studies in forests have shown that parasitoid abundance and diversity can be regulated bottom-up by increasing host diversity and abundance via plant diversity $[75,76]$, and that this can result in higher parasitism rates of herbivores [76]. Recent studies confirmed these patterns, but showed that tree species richness is not necessarily the main driver [77]. Additional components of tree diversity, such as tree functional [78•], phylogenetic [14•], or structural diversity [17•], may better explain variation in parasitoid diversity and abundance than tree species richness. However, positive relationships between plant and parasitoid diversity in forests are not universal. Abdala-Roberts et al. [79] found in a tree diversity experiment no effect of tree species richness and mahogany genetic diversity on parasitoid species richness and parasitism rates of a dominant herbivore on mahogany. These findings were possibly due to the fact that the parasitoids were largely generalists able to use different herbivore hosts and therefore unaffected by changes in herbivore diversity or composition with changing tree diversity. This points to the effects of diet specialization as a further moderator of how the "enemies" hypothesis applies to natural enemy communities in forests $[80,81]$ and emphasizes the need for more studies on specialized natural enemy taxa, which appear underrepresented in the literature so far.

\section{Birds and Bats}

In addition to predatory arthropods, vertebrate predators can play an important role in top-down control in forest ecosystems, with potentially larger effects of insectivorous birds in boreal and temperate regions than in the tropics [82, 83]. This indicates that the importance of different groups of predators, and thus their relevance for testing the "enemies" hypothesis, can vary across regions.

Bird and bat abundance (or activity, in the case of bats) and species richness were not related to tree species richness in an observational study in Germany [84••]. For a further observational study across Europe, bird species richness and abundance were significantly negatively related to tree species richness, but positively related to tree functional diversity, which mediated tree species richness effects [13]. Here, bat activity and species richness were unrelated to tree species richness and tree functional diversity, but negatively associated with the vertical heterogeneity of forest strata. In a boreal tree diversity experiment, bird predation of artificial caterpillars increased with tree species richness at the scale of directly neighboring trees, potentially due to easier access to prey [85]. In contrast, plot-level predation was unrelated to tree species richness and decreased with increasing tree height variability [85]. At both spatial scales, tree species identity strongly influenced predation rates. Tree species identity effects were also indicated in a bird exclusion experiment in mature temperate forest stands, where herbivory on oaks (but not on two other tree species) increased with the proportion of conspecifics in the overstory (i.e., in a less heterogeneous environment; [86]).

In a subtropical forest experiment, bird predation likewise increased with tree species richness for only one out of three tested tree species [87]. Higher abundance as well as functional and phylogenetic diversity of birds and higher predation rates were found in tree mixtures compared to monocultures in a tropical tree diversity experiment [88]. Interestingly, bird predation can be related to herbivore diet specialization [89]. This indicates that not only the degree of specialization of predators but also the diet breadth of the prey organisms (and the associated probability of being found by predators [26]) can influence results of plant-herbivore-predator interactions.

\section{Multi-taxon Approaches and Synthesis}

Several studies have attempted to analyze patterns of overall predator (and parasitoid) species richness and abundance, either by pooling data across taxa (which might, however, mask taxon-specific patterns) or by simultaneously addressing responses by different taxa. Considering the heterogeneity of results for individual taxa, it might not be surprising that multi-taxon approaches did not find a consistent pattern. Across 150 managed forest stands in Germany, the species richness of arthropod predators specialized to forests correlated positively with tree species richness, while the overall arthropod predator abundance and species richness were 
unrelated to tree diversity and showed a strong influence of tree species identity instead [84••]. In a young temperate tree diversity experiment, overall predator abundance was not related to tree species richness, but abundances increased with higher tree phylogenetic diversity [90]. Likewise, overall predator abundance and species richness were indirectly related to tree species richness in a subtropical tree diversity experiment [17•], where predator species richness increased with tree functional diversity while predator abundance decreased with tree structural diversity (potentially because uniform structure promoted dominant web-building spiders [17•]). Similar results were found in a natural subtropical forest, where enemy species richness was positively related to tree phylogenetic diversity, but not to tree species richness, which was nevertheless positively correlated with phylogenetic diversity [14•].

While these studies provide valuable insight into multitaxon relationships and include a larger share of the enemies that can exert top-down control in forest ecosystems, they cannot, similar to taxon-specific studies, account for potential interactions among different predatory taxa (see below). For example, if certain taxa have a disproportionate effect on the biocontrol of important herbivores, pooling data of many disparate taxa might potentially mask the role of individual predatory taxa. However, if many predators together contribute in additive or facilitative ways to top-down regulation, studies on overall predator diversity can provide insight into a larger share of potential actors in natural biocontrol (sensu [91]).

Overall, the recent literature for individual enemy taxa and for multi-taxon approaches suggests that patterns for forest ecosystems are not consistent. In some groups (e.g., ants), positive relationships with plant diversity generally seem to be more pronounced than in others (e.g., spiders). While a publication bias towards reporting significant relationships might influence the literature, this seems unlikely considering the many studies reporting a lack of tree diversity effects. In this context, a focus on species richness as a measure of biodiversity (both for trees and for predators) might fall short of assessing the relevance of the "enemies" hypothesis for forests. Incorporating alternative components of biodiversity, such as functional, phylogenetic, or structural diversity, may provide more nuanced and mechanistic inference. Importantly, the "enemies" hypothesis predicts that predator populations are more stable and predators are more efficient in more complex vegetation. Most studies only indirectly assess these relationships by looking at predator abundances and diversity or by assessing artificial prey, i.e., metrics that are not necessarily strongly related to population stability and performance. Furthermore, almost all studies sample only one or few time points, which makes it difficult to capture temporal dynamics (stability vs. fluctuations) in resources and populations that could influence the outcome of "enemies" hypothesis tests.

\section{Exploring Potential Factors Confounding the "Enemies" Hypothesis in Forests}

One main aim of this study was to synthesize the most current literature (published within the last 5 years) for an up-to-date overview of recent developments in the field. The limited number of publications precluded a formal meta-analysis that is beyond the scope of this review (see [23] for the most recent meta-analysis on relationships between plant and arthropod diversity). Nevertheless, there are several plausible explanations for why relationships in forests are highly heterogeneous (Table 1), which will be elaborated on in the next paragraphs. For this, we derive common themes from the taxon-specific summaries given above.

\section{Timing and Phenology}

Many forests are located in seasonal climates, where resource availability and arthropod populations fluctuate over the course of the seasons. This applies to all temperate and boreal forests but also to many tropical and subtropical forests such as monsoon or dry forests. In temporally unstable ecosystems, shifts in relationships between tree diversity, herbivores, and predators during forest phenology are likely, but remain virtually unexplored. In a mature beech (Fagus sylvatica) forest in Germany, relative predator abundance increased with tree diversity only early but not late in the growing season [34], indicating that "enemies" hypothesis effects may be most pronounced during peak conditions when herbivore abundance is highest. If such seasonal shifts are widespread, time of data collection and sampling may at least partly explain the observed variability among studies. The often densitydependent response of natural enemies to herbivore population density [97], which is expected to be stronger for more specialized enemies, may play a role in this context. While density dependence influences herbivore population dynamics [98], this extensive topic goes beyond the scope of this review.

\section{Latitude and Climate}

Plant, herbivore, and predator diversity show steep latitudinal gradients with generally highest species numbers at low latitudes (e.g., [92]). Tree diversity in tropical forests is orders of magnitude higher than in, e.g., boreal forests, and differences in absolute and relative tree diversity may at least theoretically influence "enemies" hypothesis studies. Even though herbivore density increases towards the equator, there is no consensus whether leaf damage is systematically related to latitude [99]. Predator activity correlates at broad spatial scales with latitude, with highest activity - which is often taken as a proxy for actual predation — in the tropics [83]. Regionally, the level of leaf damage is more variable. For example, in eastern North 
Table 1 Overview on factors potentially influencing the predictions of the "enemies" hypothesis in forests

\begin{tabular}{|c|c|c|}
\hline Influencing factor & Potential mechanism & Selected references \\
\hline Timing and phenology & Seasonal fluctuations in resources & {$[34]$} \\
\hline Latitude and climate & $\begin{array}{l}\text { Species diversity and trophic interactions increase } \\
\text { towards the equator }\end{array}$ & {$[83,92,93]$} \\
\hline Type of study & $\begin{array}{l}\text { Structural differences between natural forests and } \\
\text { tree diversity experiments }\end{array}$ & {$[29]$} \\
\hline Trophic complexity & Intraguild predation & {$[25,94]$} \\
\hline Identity effects & Tree or predator identity overrule tree diversity & {$[37,85]$} \\
\hline Non-tree plant species & $\begin{array}{l}\text { Diversity of non-woody plants drives the "enemies" } \\
\text { hypothesis }\end{array}$ & {$[95,96]$} \\
\hline Measure of diversity & $\begin{array}{l}\text { Functional and (phylo)genetic diversity more } \\
\text { influential than species richness }\end{array}$ & {$[14 \bullet, 17 \bullet]$} \\
\hline
\end{tabular}

America, herbivory decreased with latitude [100], potentially reflecting higher top-down control by predators in warmer climates (which also have more tree species) [93]. This may be related to the higher activity of ectothermic arthropods with increasing temperature, giving mobile predators energetic advantages over mostly sedentary herbivores (e.g., caterpillars). Nevertheless, a purely energetic perspective on geographic variation in herbivory is too simplistic. At tree species level, damage and defense traits covary with climate [101], which may interact with top-down control, but there seems to be no consistent difference in tree diversity effects on predators between lower and higher latitudes. Considering that many of these studies were conducted at the level of individual forest stands, other factors may modify latitudinal effects on predators.

\section{Type of Study (Tree Diversity Experiment vs. Natural Stand)}

A growing number of tree diversity experiments (e.g., within the TreeDivNet consortium, [29]), where the number of tree species planted per area is manipulated, have recently allowed to mechanistically test ecological hypotheses in response to tree diversity in young forest stands. As these experiments permit the identification of causal relationships, it is not surprising that a substantial number of contemporary "enemies" hypothesis studies were conducted in tree diversity experiments (e.g., [17•, 35, 37, 61, 63, 70, 90, 102]). In turn, in natural and managed mature forest stands, tree diversity often co-varies with many abiotic and biotic environmental properties, making it more challenging to separate diversity effects per se.

Initial experimental studies and meta-analyses in forests suggested that higher predator diversity and stronger topdown control with increasing tree diversity are primarily found in systems with low overall tree diversity [15, 33]. Thus, the outcome of the "enemies" hypothesis could depend on the type and diversity of the forest, with theoretically stronger a priori expectations (and notably the requisites to obtain causality) for tree diversity experiments, where trees are planted regularly and have the same age (but note that even the most diverse planted tree stands do often not reach the tree diversity of natural forests, especially at low latitudes). Tree diversity experiments usually include monocultures and other low-diversity mixtures, and the relative increase in tree diversity for each added tree species is larger when diversity is low, which may influence relationships with natural enemies. For example, plot tree diversity increased ant diversity in experimental [61••] and natural forests [35] in southeast China. However, increases in natural forests were weaker, which may either indicate that natural community assembly dampens "enemies" hypothesis effects or might reflect the stronger relative increase in tree species richness in the diversity experiment.

However, "enemies" hypothesis effects seem not to be systematically stronger in tree diversity experiments. Studies found positive (e.g., [61••, 70, 102]) as well as neutral (e.g., $[17 \bullet, 45,63,79,103])$ and mixed (e.g., [37, 90]) relationships between tree diversity and predators in such experiments. Similarly, in natural stands, the full range of possibilities was reported, from increases of predator abundance and diversity with tree diversity $[14 \bullet, 35,62]$ to decreases [36], with several studies also finding no effects (e.g., [84••]). In summary, and bearing in mind the differences between experimental and observational studies, the type of study system might not determine outcomes in the literature regarding the "enemies" hypothesis. As all tree diversity experiments are still relatively young when compared to natural forests and have not yet acquired features of mature forests (e.g., deadwood, microhabitats), it will be interesting to see whether results are consistent over time and hold once tree diversity experiments mature and enter succession. Repeated sampling in tree diversity experiments, where tree composition is known and temporarily stable, will also be one possible approach to generate long-term data, which are, for example, necessary to investigate resource dynamics and density dependence in enemy populations or to perform systematic comparisons across ecosystems. 


\section{Trophic Complexity}

Linear food chains with organisms in one trophic level only consuming from the next lower trophic level are not the rule in nature. For example, many predators, such as spiders or insectivorous birds, partly target other predators, a phenomenon termed intraguild predation (sensu $[25,94]$ ). Tree diversitymediated effects on herbivores might therefore depend on how tree diversity influences intraguild predation [25]. Individual predator taxa can respond differently to tree diversity, which may change predator community structure and interactions, but there is only limited data on intraguild interactions in forests. For example, the presence of ants can indirectly shift spider communities [60] from active hunters (more vulnerable to ants) to web builders (less vulnerable), with stronger changes in more diverse forests [39], giving some insight into how tree diversity may relate to intraguild interactions. In turn, different enemies can also be complementary, for example, when birds and ants as generalized predators have additive effects on caterpillar suppression as long as bird predation on ants is limited [40••].

A further dimension of trophic complexity may arise when predators are facultatively omnivorous [104], which is especially noteworthy for ants that consume honeydew from sapsucking Hemiptera [54, 105]. However, the predaciousness of ants may - in line with the "enemies" hypothesis - increase with tree diversity [106]. As for intraguild predation, such diversity-dependent changes in indirect relationships may contribute to explaining why "enemies" hypothesis relationships in forests are highly heterogeneous.

\section{Testing of the "Enemies" Hypothesis Is (Often) Imprecise}

Root's [20] original formulation of the "enemies" hypothesis was derived from comparing "simple" with "diverse" habitats (Box 1). Diversity and complexity/heterogeneity were treated synonymously. Without doubt, plant diversity increases many components of habitat heterogeneity (e.g., [17•]) but most formal tests of the "enemies" hypothesis have focused on plant diversity per se (usually as plant species richness). This ignores that habitat properties beyond plant species richness may be relevant for natural enemy populations and variations therein, a view already expressed by Root [20] because "diverse habitats offer many important requisites for adult parasitoids and predators [...], that are not available in a monoculture".

However, forests are constituted by structurally complex and long-lived organisms (i.e., trees) that even at low diversity maintain a comparatively high degree of complexity and heterogeneity. The high biomass and the many resources connected to an individual tree give them the character of "keystone structures" (sensu [107]). Consequently, the relationships postulated by the "enemies" hypothesis might be weak in forests as even species poor stands (including monospecific stands) have already a relatively high degree of complexity that allows for the existence of diverse predator communities. This assumption would also fit to the so far accumulated evidence that support for the "enemies" hypothesis comes predominately from comparatively simple ecosystems (such as agroecosystems and grasslands) [23, 24]. In the following, we will explore how (mostly tree-related) properties of species might relate to the "enemies" hypothesis.

\section{Identity Effects}

The outlined keystone properties of trees suggest that effects exerted by the identity and particular traits of a tree species can be important for shaping relationships with predators. Trees with distinct traits are known to increase or decrease predator abundance and diversity, partly explaining the variable study outcomes regarding the "enemies" hypothesis. One example are trees with extrafloral nectaries, which are common in (sub)tropical forests [53]. These trees engage in a food-forprotection mutualism by offering nutritious nectar in vegetative plant parts that attracts particularly ants $[108,109]$. Thus, the presence of extrafloral nectary trees may increase ant density, with plants benefiting through reduced damage and increased reproduction [59]. While trees with extrafloral nectaries do not generally grow faster or have higher survival than trees without [110], extrafloral nectar can facilitate top-down control on co-occurring trees lacking this defense trait [111], which may facilitate community-level tree growth [112]. Nectar is generally an important food supplement for nonant predators and parasitoids [113,114], making it likely that the presence of extrafloral nectar trees interferes with "enemies" hypothesis effects. Nevertheless, identity effects can also be negative. For example, the presence of exotic Douglas fir (Pseudotsuga menziesii) decreased spider abundance independently of tree species richness when this tree species was included in mixed experimental plantings [37].

Identity effects are not restricted to single species and can arise from specific tree compositions that overrule tree diversity in explaining natural enemies and top-down control [9]. Most evidence comes from mixing conifers with broadleaved trees [33], where mixtures had higher parasitoid abundance [115] and overall predator richness [84••]. For the pine sawfly (Neodiprion sertifer) in Scandinavia, mortality rates were higher in mixed stands than in pine monocultures [116], which was mediated top-down by ant abundances ([117], see also [9]). In the same observational system, parasitism rates of sawfly larvae increased with host tree size [11], suggesting size-dependent identity effects. Similarly, predators may preferably forage on specific tree species, which can influence the relative abundance of predator guilds. This has been shown for birds [85] in tree diversity experiments as trees 
with dense canopies may be avoided by birds and thus have more predatory arthropods, likely because bird movement is hindered [118].

The "enemies" hypothesis essentially makes predictions at the community level. Yet, populations of individual predator species may react differently to tree diversity. While overall predator abundance is predicted to increase with tree diversity, individual numbers for some enemy species may also decrease in more diverse forest stands, as has been shown in observational studies for parasitoids of spruce budworm [80] and for specialist vs. generalist enemies of pine sawfly [81]. Such species-specific responses are conceptionally equivalent to identity effects (this time exerted by predators), for example, when tree diversity benefits a dominant predator species with subsequent influences of predator identity on the entire species community (e.g., [61••, 106]).

\section{Non-tree Plant Species}

Even though trees dominate by biomass, they are not the only plant life form thriving in forests and "enemies" hypothesis effects may go beyond trees. In temperate and boreal forests with relatively low tree species richness, understory herb diversity can be considerably larger than tree diversity. Thus, tests of the "enemies" hypothesis only considering relationships with tree diversity may miss parts of the plant diversityrelated response of predators (e.g., [64]). While the relative importance of understory vegetation in comparison to trees is hard to gauge, many parasitoids depend on nectar from flowering herbs and nectar supply can be higher and temporarily more stable when understory plant diversity is high [95]. For example, in willow short rotation coppice, flowering understory weeds improved the biological control of a pest (blue willow beetle Phratora vulgatissima) by increasing predator and parasitoid diversity [96], indicating how non-tree plants can relate to the "enemies" hypothesis. Likewise, in tropical forests, epiphytes and climbing plants can be diverse and constitute habitats for many predators [119], but have not been researched in regard to the "enemies" hypothesis.

\section{Measure of Diversity}

Traditionally, plant diversity has been quantified as species richness, which was also the measure of choice for most "enemies" hypothesis studies. While species richness is intuitive, it is unlikely the number of species per se that shapes the properties of a forest, but the (dis)similarity in the traits and niches related to the trees (sensu $[50,51]$ ). Thus, functional and phylogenetic diversity, which, respectively, quantify expressed traits and evolutionary relatedness of tree communities, can be superior to species richness when investigating bottom-up effects of tree diversity $[14,17 \bullet]$.
The same argument can be made for a top-down perspective, and some of the inconsistencies among studies may in fact arise from the use of very different metrics to quantify natural enemy diversity or top-down impact (from species richness to diversity indices, from abundance or activity to predation rates). Many studies assessed species richness or abundance of natural enemies, which both do not necessarily relate to herbivore control. Species richness, for example, lacks information about functionality or potential intraguild interactions, which could make relationships between enemy species richness and top-down control highly taxon-specific $[120,121]$. The same applies to natural enemy abundance (including activity-dependent proxies such as individual counts from the many activity-dependent trap types for arthropods). Direct measurements of predation rates have likewise methodological challenges, but are increasingly being used as alternative metrics of top-down impact [122•]. Even when used for the same data set, differences in metrics can lead to potentially contrasting conclusions [36, 48], indicating that careful interpretation of research outcomes and comparison among studies is required. For further research, it may be important that evidence is accumulating which shows that predator functional diversity might be more relevant for herbivore reduction than predator species richness [123]. Moreover, observational studies in forests have started to relate diversity measures beyond species richness to predation (e.g., [124]). As research on functional and phylogenetic diversity is just beginning to thrive [14•], future experimental work will likely clarify whether functional and phylogenetic diversity of trees and predators can consolidate tests of the "enemies" hypothesis.

While this review mostly discusses effects of interspecific diversity, tree diversity also varies at the intraspecific level. Effects of plant genetic diversity on predator diversity can be as large as effects of plant species diversity [125]. For forests, tree genetic diversity has only been evaluated in few tree diversity experiments. Mostly, there was no relationship between tree genetic diversity and predators $[45,79,103,126]$ but at least one study [102] found an increase of general predator species richness (but not abundance) when genetic diversity was higher.

\section{Further Sources of Heterogeneity in Forests Beyond Tree Diversity}

In most natural forests, tree diversity is just one component of complexity and heterogeneity. The number of tree species relates to many classical ecological theories [127] that predict changes in herbivore communities such as the "more individuals hypothesis" [128] or the "resource concentration hypothesis" ([20], postulated alongside the "enemies" hypothesis), which may all feed back to predators. A review of these theories and hypotheses is beyond the scope of our review. 
Likewise, the manifold environmental influences on tree and predator diversity (see also the sections "Type of study" and "Latitude and climate") cannot be covered here. Well-known anthropogenically induced examples included past and present land use (e.g., [129]) or the time of succession since the last major disturbance event (e.g., [14•]) in forests often timber extraction. Interestingly, top-down control by natural enemies can depend on successional age [130], but in natural systems, it is often not possible to separate such environmental effects from tree diversity effects.

\section{Implications for Mixed Species Forestry}

Our review summarizes findings of basic research that may have direct implications for forest management. Promoting mixed species stands is considered a suitable approach to addressing future challenges imposed by climate change $[5,16]$. Higher tree diversity often strengthens functions and services in forests $[3,19,131,132]$, provides resistance against exotic species [133], or increases overall biodiversity [13, 17•]. However, our review suggests that stand diversification does not automatically result in stronger top-down control by predators. Different predatory taxa may respond variably to increased tree diversity and many factors may modify the relationships between tree diversity and predators. Certainly, one important conclusion of our review is that a general increase in tree species richness per se will not necessarily generate the highest biocontrol benefits, as tree species identity, functional, phylogenetic, and structural diversity all play important roles in modifying plant-herbivorepredator relationships. It is therefore sensible to carefully disentangle how these different components of tree diversity work together in influencing predator communities and to identify particularly suitable mixture types. Such an approach has also been advocated for economic purposes in a multifunctional framework [134]. Increasing biocontrol services is only one, albeit important, aspect to manage forests sustainably and to achieve multifunctionality, where a wide range of potential trade-offs have to be considered $[132,135]$.

For an effective implementation, it will also be important to better understand how natural enemies contribute to controlling pest outbreaks, which frequently impact forestry [136]. Root [20] stated that "by rapidly checking outbreaks [...] predators and parasites would prevent the potentially dominant herbivore species from monopolizing the available resources." Some studies suggest that predators are able to prevent or at least to diminish pest outbreaks (see, e.g., [137, 138]). However, natural enemies can also become saturated in such situations and their population responses will lag behind [139]. Considering the variable results for tree diversity effects on predators, the impact of planting tree mixtures on the effectiveness of natural enemies in pest outbreak situations remains unclear (see also [80, 136, 139].
In this context, the resource concentration hypothesis comes into play, which postulates that specialized herbivores will have difficulties to locate their host plants in more diverse plant communities and will therefore cause less damage in plant mixtures [20]. In effect, resource concentration and natural enemies may simultaneously influence herbivore communities $[10,15]$, but are difficult to separate without simultaneously manipulating plant and natural enemy communities. Nevertheless, the promotion of specific enemy taxa via stand diversification is possible in general, although the effects can be dependent on the region and the type of forest.

An important point to consider is that the predictions of the "enemies" hypothesis for forests are not limited to tree diversity, as habitat complexity is not solely dependent on tree diversity. For example, stand structural diversity established by the type of harvesting, causing, e.g., variability in tree height and gap dynamics, might have an effect (see also [17•]) and managing for complexity is expected to facilitate positive outcomes beyond predators [140]. Moreover, promoting habitat structures such as dead wood diversity (including dead wood type) may not only increase strictly dead wood-associated predators, but generalist predators as well (e.g., spiders [141]).

For all these measures, an understudied key question is the spatial scale at which management can be most effectively implemented. Scale dependence, a general ecological phenomenon, is also relevant for natural enemies. Whether promoting small-scale diversification or larger-scale heterogeneity is more important to promote predators, parasitoids, and their top-down effects on herbivores requires further research $[61 \bullet \cdot, 90]$. Small-scale variation in habitat structure can be important because interactions between individuals, such as individual predation events, take place locally (e.g., [85]). However, larger-scale heterogeneity determines variability at the stand level (and beyond), and the overall diversity and functional variability of predators in forests may strongly depend on management concepts that integrate heterogeneity and diversity across spatial scales $[61 \bullet \bullet]$.

\section{Research Needs}

Our synthesis of the current "enemies" hypothesis literature in forest ecosystems suggests promising future research fields. In addition to the specific research questions already identified, there are several key knowledge gaps that should be addressed to more comprehensively understand if and under which circumstances tree diversity increases natural enemy populations and how this relates to the control of herbivores.

Testing Predation and Herbivore Control Predator abundance or diversity is not necessarily the most suitable surrogate of the "enemies" hypothesis, as it is often unclear whether they translate into higher herbivore control, which would require 
direct measurements of predation pressure [142]. In recent years, indirect means for assessing predation have become popular, especially by scoring attack marks on artificial caterpillars made from plasticine [82, 83, 87, 124, 143]. However, whether or not this method allows inference on true predation pressure is questionable. Marks can come from a wide variety of non-predator taxa, and enemies that locate prey with nonvisual cues may not recognize plasticine "prey" [122•, 144]. Even though logistically more challenging, research quantifying top-down control in relation to tree diversity with more realistic methods such as living sentinel prey is desirable.

Disentangling Mechanisms Most past research has been correlative and the evidence base for the mechanisms behind "enemies" hypothesis relationships is low. For example, more stable microclimates in more diverse forest stands facilitating natural enemy activity have been postulated (e.g., [14•]) but remain to be tested. Likewise, increased functional complementarity among different predators is commonly assumed (e.g., [40••]), but tests are almost exclusively restricted to exclusion experiments. Thus, approaches that go beyond species richness and abundance by including functional and phylogenetic diversity across trophic levels [8•, 14•, 145] will contribute to a more mechanistic understanding.

Incorporating Behavioral Effects Natural enemies affect their prey not only directly via consumption but also indirectly by inducing behavioral changes, which may lower herbivore effectiveness and damage. For vertebrates, this phenomenon, the "landscape of fear," is well-understood and an important component of the net effect of predators (e.g., [146]). For arthropods, similar inference is likely, for example, when the mere presence of predator cues hinders egg-laying or deters herbivores (e.g., [147]). Studying behavioral interactions under different tree diversity will be important to understand non-consumptive effects. Furthermore, predators can also influence non-herbivorous damage-causing organisms, for example, when ant activity suppresses plant pathogens [148]. Whether or not this is diversity-dependent is at present unknown, but could be an ecologically relevant extension of the "enemies" hypothesis.

Extending Research to the Canopy and Soil For logistic reasons, most studies have sampled in the understory or on the forest floor. Tree canopies are only sparsely investigated, at least for mature forests [74]. However, a substantial part of trophic interactions occurs in tree crowns where most of the foliage is concentrated. Arthropod communities differ markedly between canopy and ground strata (e.g., [149, 150]). Without further data (e.g., obtained from fogging) from the canopy, it will be difficult to draw broader conclusions on the relationship between tree diversity, natural enemies, and topdown control. Like the canopy, the soil stratum is severely understudied. Belowground taxa respond differently to forest features than aboveground taxa [84••] and many damaging species complete at least part of their life history in the soil. Even though top-down effects can structure belowground communities [151], it is unknown whether "enemies" effects apply belowground (but see [152]). Thus, future research across forests strata is needed.

Including Understudied Life Stages All life stages of herbivores, from egg to imago, are attacked by enemies, with many being specialized to a particular life stage. So far, most research in forests has focused on the influence of predators on herbivore larvae, as they cause a major part of visible damage. Nevertheless, top-down control targets all life stages. In perennial systems, assessing mortality over the whole herbivore life-cycle is important, as relative predation pressure can shift and be highly variable among stages [153]. For example, substantial predation and parasitism affects eggs and pupae, which are difficult to sample and often not included in studies. Because "enemies" effects can be restricted to individual life stages [154], a holistic approach across stages could provide more conclusive tests of the "enemies" hypothesis.

Manipulating Natural Enemy Diversity So far, the "enemies" hypothesis has mostly been tested bottom-up by investigating the influence of tree diversity. Nevertheless, Root's [20] formulation includes a top-down element, by assuming that higher natural enemy abundance and diversity reduce herbivores. Manipulations of predator diversity (note that separating effects of predator diversity from predator abundance is important, [88]) are logistically challenging and rely largely on experiments that reduce or exclude certain species or functional groups, e.g., by locally preventing ant foraging with sticky barriers or by using nets to restrict birds. Very few experiments in forests have tried to directly manipulate predator abundance and diversity at the stand level [142, 155]. Possible approaches include adding entire ant colonies [156] or providing nesting opportunities for solitary wasps [157]. Even though not feasible in all situations and for all taxa, manipulations of predator diversity and functional composition could provide deeper insight into the causality of the "enemies" hypothesis. To minimize confounding environmental influences on natural enemies $[8 \bullet, 29]$, such predator experiments might be most promising in tree diversity experiments.

\section{Conclusions}

Research on the "enemies" hypothesis in forests is mostly restricted to generalists and has revealed a broad variety of possible outcomes, indicating that the literal formulation of this ecological concept cannot directly be applied to forest 
habitats (see also [23]). Our synthesis of the literature highlights the many properties of ecosystems (e.g., latitude), trees (e.g., identity effects), and natural enemies (e.g., intraguild predation) that may influence the relationship between tree diversity, predators, and top-down control. In order to scientifically inform how forest management can increase predator populations, it will be important to investigate how the inherent complexity of forests interacts with the predictions made by the "enemies" hypothesis. By doing so, it might be possible to disentangle the ecological conditions required for effective biological control of potential pest species in forests.

Acknowledgments We thank the editor Bastien Castagneyrol for his initiative and for encouraging us to write this review. The manuscript benefited from comments by three reviewers.

Funding Information Open Access funding provided by Projekt DEAL.

\section{Compliance with Ethical Standards}

Conflict of Interest Drs Staab and Schuldt state that there are no conflicts of interests to declare.

Human and Animal Rights and Informed Consent This article does not contain any studies with human or animal subjects performed by any of the authors.

Open Access This article is licensed under a Creative Commons Attribution 4.0 International License, which permits use, sharing, adaptation, distribution and reproduction in any medium or format, as long as you give appropriate credit to the original author(s) and the source, provide a link to the Creative Commons licence, and indicate if changes were made. The images or other third party material in this article are included in the article's Creative Commons licence, unless indicated otherwise in a credit line to the material. If material is not included in the article's Creative Commons licence and your intended use is not permitted by statutory regulation or exceeds the permitted use, you will need to obtain permission directly from the copyright holder. To view a copy of this licence, visit http://creativecommons.org/licenses/by/4.0/.

\section{References}

Papers of particular interest, published recently, have been highlighted as:

- Of importance

• Of major importance

1. Seibold S, Gossner MM, Simons NK, Blüthgen N, Müller J, Ambarli D, et al. Arthropod decline in grasslands and forests is associated with landscape-level drivers. Nature. 2019;574:671-4. https://doi.org/10.1038/s41586-019-1684-3.

2. Barbati A, Marchetti M, Chirici G, Corona P. European Forest Types and Forest Europe SFM indicators: tools for monitoring progress on forest biodiversity conservation. For Ecol Manag. 2014;321:145-57. https://doi.org/10.1016/j.foreco.2013.07.004.

3. Brockerhoff EG, Barbaro L, Castagneyrol B, Forrester DI, Gardiner B, Gonzalez-Olabarria JR, et al. Forest biodiversity, ecosystem functioning and the provision of ecosystem services. Biodivers Conserv. 2017;26:3005-35. https://doi.org/10.1007/ s10531-017-1453-2.

4. Terborgh J, Lopez L, Nunez P, Rao M, Shahabuddin G, Orihuela $\mathrm{G}$, et al. Ecological meltdown in predator-free forest fragments. Science. 2001;294:1923-6. https://doi.org/10.1126/science. 1064397.

5. Klapwijk MJ, Bylund H, Schroeder M, Björkman C. Forest management and natural biocontrol of insect pests. Forestry. 2016;89: 253-62. https://doi.org/10.1093/forestry/cpw019.

6. Nyffeler M, Birkhofer K. An estimated 400-800 million tons of prey are annually killed by the global spider community. Sci Nat. 2017;104:30. https://doi.org/10.1007/s00114-017-1440-1.

7. Seidl R, Schelhaas MJ, Rammer W, Verkerk PJ. Increasing forest disturbances in Europe and their impact on carbon storage. Nat Clim Chang. 2014;4:806-10. https://doi.org/10.1038/ nclimate2318.

8. Jonsson M, Kaartinen R, Straub CS. Relationships between natural enemy diversity and biological control. Curr Opin Insect Sci. 2017;20:1-6. https://doi.org/10.1016/j.cois.2017.01.001 Outlines how incorporating a trait-based approach can increase our mechanistic understanding of predator-prey interactions.

9. Riihimäki J, Kaitaniemi P, Koricheva J, Vehviläinen H. Testing the enemies hypothesis in forest stands: the important role of tree species composition. Oecologia. 2005;142:90-7. https://doi.org/ 10.1007/s00442-004-1696-y.

10. Jactel H, Bauhus J, Boberg J, Bonal D, Castagneyrol B, Gardiner $\mathrm{B}$, et al. Tree diversity drives forest stand resistance to natural disturbances. Curr For Rep. 2017;3:223-43. https://doi.org/10. 1007/s40725-017-0064-1.

11. Klapwijk MJ, Björkman C. Mixed forests to mitigate risk of insect outbreaks. Scan J For Res. 2018;33:772-80. https://doi.org/10. 1080/02827581.2018.1502805.

12. Langellotto GA, Denno RF. Responses of invertebrate natural enemies to complex-structured habitats: a meta-analytical synthesis. Oecologia. 2004;139:1-10. https://doi.org/10.1007/s00442004-1497-3.

13. Ampoorter E, Barbaro L, Jactel H, Baeten L, Boberg J, Carnol M, et al. Tree diversity is key for promoting the diversity and abundance of forest-associated taxa in Europe. Oikos. 2020;129:13346. https://doi.org/10.1111/oik.06290.

14. Staab M, Bruelheide H, Durka W, Michalski S, Purschke O, Zhu $\mathrm{CD}$, et al. Tree phylogenetic diversity promotes host-parasitoid interactions. Proc R Soc B. 2016;283:20160275. https://doi.org/ 10.1098/rspb.2016.0275 Extends the 'enemies' hypothesis to tree phylogenetic diversity by showing that tree phylogenetic diversity is superior to tree species richness in increasing parasitism rates.

15. Jactel H, Brockerhoff EG. Tree diversity reduces herbivory by forest insects. Ecol Lett. 2007;10:835-48. https://doi.org/10. 1111/j.1461-0248.2007.01073.x.

16. Ammer C. Diversity and forest productivity in a changing climate. New Phytol. 2019;221:50-66. https://doi.org/10.1111/nph.15263.

17. Schuldt A, Ebeling A, Kunz M, Staab M, Guimaraes-Steinicke C, Bachmann D, et al. Multiple plant diversity components drive consumer communities across ecosystems. Nat Commun. 2019;10:1460. https://doi.org/10.1038/s41467-019-09448-8 Emphasizes the importance of considering the multifaceted concept of tree diversity when testing the 'enemies' hypothesis.

18. Schowalter TD, Noriega JA, Tscharntke T. Insect effects on ecosystem services-introduction. Basic Appl Ecol. 2018;26:1-7. https://doi.org/10.1016/j.baae.2017.09.011.

19. Schuldt A, Assmann T, Brezzi M, Buscot F, Eichenberg D, Gutknecht J, et al. Biodiversity across trophic levels drives multifunctionality in highly diverse forests. Nat Commun. 2018;9:2989. https://doi.org/10.1038/s41467-018-05421-z. 
20. Root RB. Organization of a plant-arthropod association in simple and diverse habitats: the fauna of collards (Brassica oleracea). Ecol Monogr. 1973;43:95-120. https://doi.org/10.2307/1942161.

21. Russell EP. Enemies hypothesis - a review of the effect of vegetational diversity on predatory insects and parasitoids. Environ Entomol. 1989;18:590-9. https://doi.org/10.1093/ee/18.4.590.

22. Bianchi FJJA, Booij CJH, Tscharntke T. Sustainable pest regulation in agricultural landscapes: a review on landscape composition, biodiversity and natural pest control. Proc R Soc B. 2006;273:1715-27. https://doi.org/10.1098/rspb.2006.3530.

23. Wan NF, Zheng XR, Fu LW, Kiær LP, Zhang Z, Chaplin-Kramer $\mathrm{R}$, et al. Global synthesis of effects of plant species diversity on trophic groups and interactions. Nat Plants. 2020;6:503-10. https://doi.org/10.1038/s41477-020-0654-y.

24. Letourneau DK, Jedlicka JA, Bothwell SG, Moreno CR. Effects of natural enemy biodiversity on the suppression of arthropod herbivores in terrestrial ecosystems. Annu Rev Ecol Evol Syst. 2009;40:573-92. https://doi.org/10.1146/annurev.ecolsys. 110308.120320 .

25. Finke DL, Denno RF. Intraguild predation diminished in complex-structured vegetation: implications for prey suppression. Ecology. 2002;83:643-52. https://doi.org/10.2307/3071870.

26. Straub CS, Simasek NP, Dohm R, Gapinski MR, Aikens EO, Nagy C. Plant diversity increases herbivore movement and vulnerability to predation. Basic Appl Ecol. 2014;15:50-8. https:// doi.org/10.1016/j.baae.2013.12.004.

27. Haddad NM, Crutsinger GM, Gross K, Haarstad J, Knops JMH, Tilman D. Plant species loss decreases arthropod diversity and shifts trophic structure. Ecol Lett. 2009;12:1029-39. https://doi. org/10.1111/j.1461-0248.2009.01356.x.

28. Breshears DD. The grassland-forest continuum: trends in ecosystem properties for woody plant mosaics? Front Ecol Environ. 2006;4:96-104. https://doi.org/10.1890/1540-9295(2006) 004[0096:TGCTIE]2.0.CO;2.

29. Grossman JJ, Vanhellemont M, Barsoum N, Bauhus J, Bruelheide $\mathrm{H}$, Castagneyrol B, et al. Synthesis and future research directions linking tree diversity to growth, survival, and damage in a global network of tree diversity experiments. Environ Exp Bot. 2018;152:68-89. https://doi.org/10.1016/j.envexpbot.2017.12. 015 .

30. van Beal SA, Philpott SM, Greenberg R, Bichier P, Barber NA, Mooney KA, et al. Birds as predators in tropical agroforestry systems. Ecology. 2008;89:928-34. https://doi.org/10.1890/061976.1.

31. Mooney KA, Gruner DS, Barber NA, van Beal SA, Philpott SM, Greenberg R. Interactions among predators and the cascading effects of vertebrate insectivores on arthropod communities and plants. Proc Natl Acad Sci U S A. 2010;107:7335-40. https:// doi.org/10.1073/pnas.1001934107.

32. Zhang YJ, Adams J. Top-down control of herbivores varies with ecosystem types. J Ecol. 2011;99:370-2. https://doi.org/10.1111/j. 1365-2745.2010.01770.x.

33. Vehviläinen H, Koricheva J, Ruohomäki K. Effects of stand tree species composition and diversity on abundance of predatory arthropods. Oikos. 2008;117:935-43. https://doi.org/10.1111/j. 2008.0030-1299.15972.x.

34. Sobek S, Scherber C, Steffan-Dewenter I, Tscharntke T. Sapling herbivory, invertebrate herbivores and predators across a natural tree diversity gradient in Germany's largest connected deciduous forest. Oecologia. 2009;160:279-88. https://doi.org/10.1007/ s00442-009-1304-2.

35. Staab M, Schuldt A, Assmann T, Klein AM. Tree diversity promotes predator but not omnivore ants in a subtropical Chinese forest. Ecol Entomol. 2014;39:637-47. https://doi.org/10.1111/ een. 12143 .
36. Schuldt A, Both S, Bruelheide H, Härdtle W, Schmid B, Zhou H, et al. Predator diversity and abundance provide little support for the enemies hypothesis in forests of high tree diversity. PLoS One. 2011;6:e22905. https://doi.org/10.1371/journal.pone.0022905.

37. Schuldt A, Scherer-Lorenzen M. Non-native tree species (Pseudotsuga menziesii) strongly decreases predator biomass and abundance in mixed-species plantations of a tree diversity experiment. For Ecol Manag. 2014;327:10-7. https://doi.org/10. 1016/j.foreco.2014.04.036.

38. Finke DL, Denno RF. Predator diversity and the functioning of ecosystems: the role of intraguild predation in dampening trophic cascades. Ecol Lett. 2005;8:1299-306. https://doi.org/10.1111/j. 1461-0248.2005.00832.x.

39. Schuldt A, Staab M. Tree species richness strengthens relationships between ants and the functional composition of spider assemblages in a highly diverse forest. Biotropica. 2015;47:339-46. https://doi.org/10.1111/btp.12209.

40.• Singer MS, Clark RE, Lichter-Marck IH, Johnson ER, Mooney KA. Predatory birds and ants partition caterpillar prey by body size and diet breadth. J Anim Ecol. 2017;86:1363-71. https:// doi.org/10.1111/1365-2656.12727 Shows how interactions among different groups of predators affect herbivores in relation to herbivore traits.

41. Fuller L, Fuentes-Montemayor E, Watts K, Macgregor NA, Bintenc K, Park KJ. Local-scale attributes determine the suitability of woodland creation sites for Diptera. J Appl Ecol. 2018;55: 1173-84. https://doi.org/10.1111/1365-2664.13035.

42. Oxbrough A, French V, Irwin S, Kelly TC, Smiddy P, O'Halloran J. Can mixed species stands enhance arthropod diversity in plantation forests? For Ecol Manag. 2012;270:11-8. https://doi.org/10. 1016/j.foreco.2012.01.006.

43. Oxbrough A, García-Tejero S, Spence J, O’Halloran J. Can mixed stands of native and non-native tree species enhance diversity of epigaeic arthropods in plantation forests? For Ecol Manag. 2016;367:21-9. https://doi.org/10.1016/j.foreco.2016.02.023.

44. Esquivel-Gómez L, Abdala-Roberts L, Pinkus-Rendon M, ParraTabla V. Effects of tree species diversity on a community of weaver spiders in a tropical forest plantation. Biotropica. 2017;49:63-70. https://doi.org/10.1111/btp.12352.

45. Abdala-Roberts L, Mooney KA, Quijano-Medina T, CamposNavarrete MJ, Gonzalez-Moreno A, Parra-Tabla V. Comparison of tree genotypic diversity and species diversity effects on different guilds of insect herbivores. Oikos. 2015;124:1527-35. https:// doi.org/10.1111/oik.02033.

46. Nadrowski K, Wirth C, Scherer-Lorenzen M. Is forest diversity driving ecosystem function and service? Curr Opin Environ Sustain. 2010;2:75-9. https://doi.org/10.1016/j.cosust.2010.02. 003.

47. Zhang JY, Bruelheide H, Chen XF, Eichenberg D, Kröber W, Xu $\mathrm{WX}$, et al. Tree diversity promotes generalist herbivore community patterns in a young subtropical forest experiment. Oecologia. 2017;183:455-67. https://doi.org/10.1007/s00442-016-3769-0.

48. Schuldt A, Bruelheide H, Durka W, Michalski SG, Purschke O, Assmann T. Tree diversity promotes functional dissimilarity and maintains functional richness despite species loss in predator assemblages. Oecologia. 2014;174:533-43. https://doi.org/10.1007/ s00442-013-2790-9.

49. Schuldt A, Baruffol M, Bruelheide H, Chen SM, Chi XL, Wall M, et al. Woody plant phylogenetic diversity mediates bottom-up control of arthropod biomass in species-rich forests. Oecologia. 2014;176:171-82. https://doi.org/10.1007/s00442-014-3006-7.

50. Srivastava DS, Cadotte MW, MacDonald AAM, Marushia RG, Mirotchnick N. Phylogenetic diversity and the functioning of ecosystems. Ecol Lett. 2012;15:637-48. https://doi.org/10.1111/j. 1461-0248.2012.01795.x. 
51. Tucker CM, Davies TJ, Cadotte MW, Pearse WD. On the relationship between phylogenetic diversity and trait diversity. Ecology. 2018;99:1473-9. https://doi.org/10.1002/ecy.2349.

52. Davidson DW, Cook SC, Snelling RR, Chua TH. Explaining the abundance of ants in lowland tropical rainforest canopies. Science. 2003;300:969-72. https://doi.org/10.1126/science.1082074.

53. Heil M. Extrafloral nectar at the plant-insect interface: a spotlight on chemical ecology, phenotypic plasticity, and food webs. Annu Rev Entomol. 2015;60:213-32. https://doi.org/10.1146/annurevento-010814-020753.

54. Staab M, Blüthgen N, Klein AM. Tree diversity alters the structure of a tri-trophic network in a biodiversity experiment. Oikos. 2015;124:827-34. https://doi.org/10.1111/oik.01723.

55. Staab M, Fornoff F, Klein AM, Blüthgen N. Ants at plant wounds: a little-known trophic interaction with evolutionary implications for ant-plant interactions. Am Nat. 2017;190:442-50. https://doi. org/10.1086/692735.

56. Campos-Navarrete MJ, Abdala-Roberts L, Munguia-Rosas MA, Parra-Tabla V. Are tree species diversity and genotypic diversity effects on insect herbivores mediated by ants? PLoS One. 2015;10:e0132671. https://doi.org/10.1371/journal.pone. 0132671.

57. Fornoff F, Klein AM, Blüthgen N, Staab M. Tree diversity increases robustness of multi-trophic interactions. Proc R Soc B. 2019;286:20182399. https://doi.org/10.1098/rspb.2018.2399.

58. Zvereva EL, Lanta V, Kozlov MV. Effects of sap-feeding insect herbivores on growth and reproduction of woody plants: a metaanalysis of experimental studies. Oecologia. 2010;163:949-60. https://doi.org/10.1007/s00442-010-1633-1.

59. Trager MD, Bhotika S, Hostetler JA, Andrade GV, RodriguezCabal MA, McKeon CS, et al. Benefits for plants in ant-plant protective mutualisms: a meta-analysis. PLoS One. 2010;5: e14308. https://doi.org/10.1371/journal.pone.0014308.

60. Katayama M, Kishimoto-Yamada K, Tanaka HO, Endo T, Hashimoto Y, Yamane S, et al. Negative correlation between ant and spider abundances in the canopy of a Bornean tropical rain forest. Biotropica. 2015;47:363-8. https://doi.org/10.1111/ btp. 12208.

61.• Skarbek CJ, Noack M, Bruelheide H, Härdtle W, von Oheimb G, Scholten T, et al. A tale of scale: community but not neighborhood tree diversity increases leaf litter ant diversity. J Anim Ecol. 2020;89:299-308. https://doi.org/10.1002/ece3.6003 Demonstrates that 'enemies' hypothesis effects are scaledependent and not restricted to the immediate neighborhood of sampling points.

62. Grevé ME, Hager J, Weisser WW, Schall P, Gossner MM, Feldhaar H. Effect of forest management on temperate ant communities. Ecosphere. 2018;9:e02303. https://doi.org/10.1002/ ecs2.2303.

63. Yeeles P, Lach L, Hobbs RJ, van Wees M, Didham RK. Woody plant richness does not influence invertebrate community reassembly trajectories in a tree diversity experiment. Ecology. 2017;98:500-11. https://doi.org/10.1002/ecy.1662.

64. Leles B, Xiao X, Pasion BO, Nakamura A, Tomlinson KW. Does plant diversity increase top-down control of herbivorous insects in tropical forest? Oikos. 2017;126:1142-9. https://doi.org/10.1111/ oik.03562.

65. Moreira X, Mooney KA, Zas R, Sampedro L. Bottom-up effects of host-plant species diversity and top-down effects of ants interactively increase plant performance. Proc R Soc B. 2012;279: 4464-72. https://doi.org/10.1098/rspb.2012.0893.

66. Nolte D, Schuldt A, Gossner M, Ulrich W, Assmann T. Functional traits drive ground beetle community structures in Central European forests: implications for conservation. Biol Conserv. 2017;213:5-12. https://doi.org/10.1016/j.biocon.2017.06.038.
67. Lange M, Türke M, Pasalic E, Boch S, Hessenmöller D, Müller J, et al. Effects of forest management on ground-dwelling beetles (Coleoptera; Carabidae, Staphylinidae) in Central Europe are mainly mediated by changes in forest structure. For Ecol Manag. 2014;329:166-76. https://doi.org/10.1016/j.foreco.2014.06.012.

68. Zou Y, Sang WG, Bai F, Brennan E, Diekman M, Lius YH, et al. Large-scale $\alpha$-diversity patterns in plants and ground beetles (Coleoptera: Carabidae) indicate a high biodiversity conservation value of China's restored temperate forest landscapes. Divers Distrib. 2019;25:1613-24. https://doi.org/10.1111/ddi.12964.

69. Barsoum N, Fuller L, Ashwood F, Reed K, Bonnet-Lebrun AS, Leung F. Ground-dwelling spider (Araneae) and carabid beetle (Coleoptera: Carabidae) community assemblages in mixed and monoculture stands of oak (Quercus robur L./Quercus petraea (Matt.) Liebl.) and Scots pine (Pinus sylvestris L.). For Ecol Manag. 2014;321:29-41. https://doi.org/10.1016/j.foreco.2013. 08.063 .

70. Jouveau S, Toigo M, Giffard B, Castagneyrol B, van Halder I, Vetillard F, et al. Carabid activity-density increases with forest vegetation diversity at different spatial scales. Insect Conserv Divers. 2020;13:36-46. https://doi.org/10.1111/icad.12372.

71. Chamagne J, Paine CET, Schoolmaster DR, Stejskal R, Volarik $\mathrm{D}$, Sebesta J, et al. Do the rich get richer? Varying effects of tree species identity and diversity on the richness of understory taxa. Ecology. 2016;97:2364-73. https://doi.org/10.1002/ecy.1479.

72. Sobek S, Steffan-Dewenter I, Scherber C, Tscharntke T. Spatiotemporal changes of beetle communities across a tree diversity gradient. Divers Distrib. 2009;15:660-70. https://doi.org/ 10.1111/j.1472-4642.2009.00570.x.

73. Normann C, Tscharntke T, Scherber C. Interacting effects of forest stratum, edge and tree diversity on beetles. For Ecol Manag. 2016;361:421-31. https://doi.org/10.1016/j.foreco.2015.11.002.

74. Nakamura A, Kitching RL, Cao M, Creedy TJ, Fayle TM, Freiberg M, et al. Forests and their canopies: achievements and horizons in canopy science. Trends Ecol Evol. 2017;32:438-51. https://doi.org/10.1016/j.tree.2017.02.020.

75. Fraser SEM, Dytham C, Mayhew PJ. Determinants of parasitoid abundance and diversity in woodland habitats. J Appl Ecol. 2007;44:352-61. https://doi.org/10.1111/j.1365-2664.2006. 01266.x.

76. Fenoglio MS, Srivastava D, Valladares G, Cagnolo L, Salvo A. Forest fragmentation reduces parasitism via species loss at multiple trophic levels. Ecology. 2012;93:2407-20. https://doi.org/10. 1890/11-2043.1.

77. Kendall LK, Ward DF. Habitat determinants of the taxonomic and functional diversity of parasitoid wasps. Biodivers Conserv. 2016;25:1955-72. https://doi.org/10.1007/s10531-016-1174-y.

78. Rodríguez A, Pohjoismäki JLO, Kouki J. Diversity of forest management promotes parasitoid functional diversity in boreal forests. Biol Conserv. 2019;238:108205. https://doi.org/10.1016/j.biocon. 2019.108205 Emphasizes the importance of parasitoids in 'enemies' hypothesis studies and shows how parasitoid functional diversity can benefit from suitable management.

79. Abdala-Roberts L, Gonzalez-Moreno A, Mooney KA, Moreira X, Gonzalez-Hernandez A, Parra-Tabla V. Effects of tree species diversity and genotypic diversity on leafminers and parasitoids in a tropical forest plantation. Agric For Entomol. 2016;18:4351. https://doi.org/10.1111/afe.12132.

80. Legault S, James PMA. Parasitism rates of spruce budworm larvae: testing the enemy hypothesis along a gradient of forest diversity measured at different spatial scales. Environ Entomol. 2018;47:1083-95. https://doi.org/10.1093/ee/nvy113.

81. Bellone D, Björkman C, Klapwijk MJ. Top-down pressure by generalist and specialist natural enemies in relation to habitat heterogeneity and resource availability. Basic Appl Ecol. 2020;43: 16-26. https://doi.org/10.1016/j.baae.2019.10.005. 
82. Sam K, Remmel T, Molleman F. Material affects attack rates on dummy caterpillars in tropical forest where arthropod predators dominate: an experiment using clay and dough dummies with green colourants on various plant species. Entomol Exp Appl. 2015;157:317-24. https://doi.org/10.1111/eea.12367.

83. Roslin T, Hardwick B, Novotny V, Petry WK, Andrew NR, Asmus A, et al. Higher predation risk for insect prey at low latitudes and elevations. Science. 2017;356:742-4. https://doi.org/10. 1126/science.aaj1631.

84.•• Penone C, Allan E, Soliveres S, Felipe-Lucia MR, Gossner MM, Seibold S, et al. Specialisation and diversity of multiple trophic groups are promoted by different forest features. Ecol Lett. 2019;22:170-80. https://doi.org/10.1111/ele.13182 A very comprehensive study showing that many properties of a forest influence natural enemy abundance and species richness.

85. Muiruri EW, Rainio K, Koricheva J. Do birds see the forest for the trees? Scale-dependent effects of tree diversity on avian predation of artificial larvae. Oecologia. 2016;180:619-30. https://doi.org/ 10.1007/s00442-015-3391-6.

86. Dekeukeleire D, Lantman IMV, Hertzog LR, Vandegehuchte ML, Strubbe D, Vantieghem P, et al. Avian top-down control affects invertebrate herbivory and sapling growth more strongly than overstorey species composition in temperate forest fragments. For Ecol Manag. 2019;442:1-9. https://doi.org/10.1016/j.foreco. 2019.03.055

87. Yang B, Li B, He YX, Zhang LP, Bruelheide H, Schuldt A. Tree diversity has contrasting effects on predation rates by birds and arthropods on three broadleaved, subtropical tree species. Ecol Res. 2018;33:205-12. https://doi.org/10.1007/s11284-017-15317.

88. Nell CS, Abdala-Roberts L, Parra-Tabla V, Mooney KA. Tropical tree diversity mediates foraging and predatory effects of insectivorous birds. Proc R Soc B. 2018;285:20181842. https://doi.org/ 10.1098/rspb.2018.1842.

89. Singer MS, Lichter-Marck IH, Farkas TE, Aaron E, Whitney KD, Mooney KA. Herbivore diet breadth mediates the cascading effects of carnivores in food webs. Proc Natl Acad Sci U S A. 2014;111:9521-6. https://doi.org/10.1073/pnas.1401949111.

90. Setiawan NN, Vanhellemont M, Baeten L, Gobin R, De Smedt P, Proesmans W, et al. Does neighbourhood tree diversity affect the crown arthropod community in saplings? Biodivers Conserv. 2016;25:169-85. https://doi.org/10.1007/s10531-015-1044-z.

91. Schmidt MH, Lauer A, Purtauf T, Thies C, Schaefer M, Tscharntke T. Relative importance of predators and parasitoids for cereal aphid control. Proc R Soc B. 2003;270:1905-9. https://doi.org/10.1098/rspb.2003.2469.

92. Becerra JX. On the factors that promote the diversity of herbivorous insects and plants in tropical forests. Proc Natl Acad Sci U S A. 2015;112:6098-103. https://doi.org/10.1073/pnas. 1418643112 .

93. Björkman C, Berggren A, Bylund H. Causes behind insect folivory patterns in latitudinal gradients. J Ecol. 2011;99:367-9. https://doi.org/10.1111/j.1365-2745.2010.01707.x.

94. Schmitz OJ. Effects of predator functional diversity on grassland ecosystem function. Ecology. 2009;90:2339-45. https://doi.org/ 10.1890/08-1919.1.

95. Russell M. A meta-analysis of physiological and behavioral responses of parasitoid wasps to flowers of individual plant species. Biol Control. 2015;82:96-103. https://doi.org/10.1016/j. biocontrol.2014.11.014.

96. Stephan JG, Albertsson J, Wang L, Porcel M. Weeds within willow short-rotation coppices alter the arthropod community and improve biological control of the blue willow beetle. BioControl. 2016;61:103-14. https://doi.org/10.1007/s10526015-9693-0.
97. Stiling P. Density-dependent processes and key factors in insect populations. J Anim Ecol. 1988;57:581-93. https://doi.org/10. 2307/4926.

98. Tylianakis JM, Romo CM. Natural enemy diversity and biological control: making sense of the context-dependency. Basic Appl Ecol. 2010;11:657-68. https://doi.org/10.1016/j.baae.2010.08. 005.

99. Salazar D, Marquis RJ. Herbivore pressure increases toward the equator. Proc Natl Acad Sci U S A. 2012;109:12616-20. https:// doi.org/10.1073/pnas.1202907109.

100. Adams JM, Zhang Y. Is there more insect folivory in warmer temperate climates? A latitudinal comparison of insect folivory in eastern North America. J Ecol. 2009;97:933-40. https://doi. org/10.1111/j.1365-2745.2009.01523.x.

101. Garibaldi LA, Kitzberger T, Ruggiero A. Latitudinal decrease in folivory within Nothofagus pumilio forests: dual effect of climate on insect density and leaf traits? Glob Ecol Biogeogr. 2011;20: 609-19. https://doi.org/10.1111/j.1466-8238.2010.00623.x.

102. Campos-Navarrete MJ, Munguia-Rosas MA, Abdala-Roberts L, Quinto J, Parra-Tabla V. Effects of tree genotypic diversity and species diversity on the arthropod community associated with bigleaf mahogany. Biotropica. 2015;47:579-87. https://doi.org/10. 1111/btp.12250.

103. Müller M, Klein AM, Scherer-Lorenzen M, Nock CA, Staab M. Tree genetic diversity increases arthropod diversity in willow short rotation coppice. Biomass Bioenergy. 2018;108:338-44. https:// doi.org/10.1016/j.biombioe.2017.12.001.

104. Roeder KA, Kaspari M. From cryptic herbivore to predator: stable isotopes reveal consistent variability in trophic levels in an ant population. Ecology. 2017;98:297-303. https://doi.org/10.1002/ ecy.1641.

105. Clark RE, Farkas TE, Lichter-Marck I, Johnson ER, Singer MS. Multiple interaction types determine the impact of ant predation of caterpillars in a forest community. Ecology. 2016;97:3379-88. https://doi.org/10.1002/ecy.1571.

106. Schuldt A, Fornoff F, Bruelheide H, Klein AM, Staab M. Tree species richness attenuates the positive relationship between mutualistic ant-hemipteran interactions and leaf chewer herbivory. Proc R Soc B. 2017;284:20171489. https://doi.org/10.1098/rspb. 2017.1489.

107. Jones CG, Lawton JH, Shachak M. Organisms as ecosystem engineers. Oikos. 1994;69:373-86. https://doi.org/10.2307/ 3545850 .

108. Koptur S. Extrafloral nectary-mediated interactions between insects and plants. In: Bernays E, editor. CRC series on insect/ plant interactions. Boca Raton: CRC Press; 1992.

109. Staab M, Methorst J, Peters J, Blüthgen N, Klein AM. Tree diversity and nectar composition affect arthropod visitors on extrafloral nectaries in a diversity experiment. J Plant Ecol. 2017;10:201-12. https://doi.org/10.1093/jpe/rtw017.

110. Muehleisen A, Queenborough SA, Alvia P, Valencia R, Fiala B. Incidence of extrafloral nectaries and their relationship with growth and survival of lowland tropical rain forest trees. Biotropica. 2016;48:321-31. https://doi.org/10.1111/btp.12310.

111. Rezende MQ, Venzon M, Perez AL, Cardoso IM, Janssen A. Extrafloral nectaries of associated trees can enhance natural pest control. Agric Ecosyst Environ. 2014;188:198-203. https://doi. org/10.1016/j.agee.2014.02.024.

112. Kröber W, Li Y, Härdtle W, Ma K, Schmid B, Schmidt K, et al. Early subtropical forest growth is driven by community mean trait values and functional diversity rather than the abiotic environment. Ecol Evol. 2015;5:3541-56. https://doi.org/10.1002/ece3. 1604.

113. Lundgren JG, Seagraves MP. Physiological benefits of nectar feeding by a predatory beetle. Biol J Linn Soc. 2011;104:661-9. https://doi.org/10.1111/j.1095-8312.2011.01729.x. 
114. Sanders D. Herbivory in spiders. In: Nentwig W, editor. Spider Ecophysiology. Berlin, Heidelberg: Springer; 2013.

115. Jäkel A, Roth M. Conversion of single-layered scots pine monocultures into close-to-nature mixed hardwood forests: effects on parasitoid wasps as pest antagonists. Eur J For Res. 2004;123: 203-12. https://doi.org/10.1007/s10342-004-0030-x.

116. Bellone D, Klapwijk MJ, Björkman C. Habitat heterogeneity affects predation of European pine sawfly cocoons. Ecol Evol. 2017;7:11011-20. https://doi.org/10.1002/ece3.3632.

117. Kaitaniemi P, Riihimäki J, Koricheva J, Vehviläinen H. Experimental evidence for associational resistance against the European pine sawfly in mixed tree stands. Silva Fenn. 2007;41:259-68. https://doi.org/10.14214/sf.295.

118. Nell CS, Mooney KA. Plant structural complexity mediates tradeoff in direct and indirect plant defense by birds. Ecology. 2019;100:e02853. https://doi.org/10.1002/ecy.2853.

119. Ellwood MDF, Foster WA. Doubling the estimate of invertebrate biomass in a rainforest canopy. Nature. 2004;429:549-51. https:// doi.org/10.1038/nature02560.

120. Sanders D, Schaefer M, Platner C, Griffiths GJK. Intraguild interactions among generalist predator functional groups drive impact on herbivore and decomposer prey. Oikos. 2011;120:418-26. https://doi.org/10.1111/j.1600-0706.2010.18924.x.

121. Michalko R, Pekár S, Entling MH. An updated perspective on spiders as generalist predators in biological control. Oecologia. 2019;189:21-36. https://doi.org/10.1007/s00442-018-4313-1.

122. Lövei GL, Ferrante M. A review of the sentinel prey method as a way of quantifying invertebrate predation under field conditions. Insect Sci. 2017;24:528-42. https://doi.org/10.1111/1744-7917. 12405 Summarizes research using artificial prey and gives important suggestions on how to quantify predation rates.

123. Greenop A, Woodcock BA, Wilby A, Cook SM, Pywell RF. Functional diversity positively affects prey suppression by invertebrate predators: a meta-analysis. Ecology. 2018;99:1771-82. https://doi.org/10.1002/ecy.2378.

124. Liu X, Wang Z, Huang C, Li M, Bibi F, Zhou S, et al. Ant assemblage composition explains high predation pressure on artificial caterpillars during early night. Ecol Entomol. 2020;45:54754. https://doi.org/10.1111/een.12826.

125. Koricheva J, Hayes D. The relative importance of plant intraspecific diversity in structuring arthropod communities: a meta-analysis. Funct Ecol. 2018;32:1704-17. https://doi.org/10.1111/13652435.13062.

126. Cao HX, Klein AM, Zhu CD, Staab M, Durka W, Fischer M, et al. Intra- and interspecific tree diversity promotes multitrophic plantHemiptera-ant interactions in a forest diversity experiment. Basic Appl Ecol. 2018;29:89-97. https://doi.org/10.1016/j.baae.2018. 03.005 .

127. Moreira X, Abdala-Roberts L, Rasmann S, Castagneyrol B, Mooney KA. Plant diversity effects on insect herbivores and their natural enemies: current thinking, recent findings, and future directions. Curr Opin Insect Sci. 2016;14:1-7. https://doi.org/10. 1016/j.cois.2015.10.003.

128. Srivastava DS, Lawton JH. Why more productive sites have more species: an experimental test of theory using tree-hole communities. Am Nat. 1998;152:510-29. https://doi.org/10.1086/286187.

129. Liu C, Guenard B, Blanchard B, Peng Y-Q, Economo EP. Reorganization of taxonomic, functional, and phylogenetic ant biodiversity after conversion to rubber plantation. Ecol Monogr. 2016;86:215-27. https://doi.org/10.1890/15-1464.1.

130. Floren A, Biun A, Linsenmair KE. Arboreal ants as key predators in tropical lowland rainforest trees. Oecologia. 2002;131:137-44. https://doi.org/10.1007/s00442-002-0874-z.

131. Gamfeldt L, Snall T, Bagchi R, Jonsson M, Gustafsson L, Kjellander P, et al. Higher levels of multiple ecosystem services are found in forests with more tree species. Nat Commun. 2013;4: 1340. https://doi.org/10.1038/ncomms2328.

132. van der Plas F, Manning P, Allan E, Scherer-Lorenzen M, Verheyen K, Wirth C, et al. 'Jack-of-all-trades' effects drive biodiversity-ecosystem multifunctionality relationships in European forests. Nat Commun. 2016;7:11109. https://doi.org/ 10.1038/ncomms11109.

133. Guo QF, Fei SL, Potter KM, Liebhold AM, Wen J. Tree diversity regulates forest pest invasion. Proc Natl Acad Sci U S A. 2019;116:7382-6. https://doi.org/10.1073/pnas.1821039116.

134. Baeten L, Bruelheide H, van der Plas F, Kambach S, Ratcliffe S, Jucker T, et al. Identifying the tree species compositions that maximize ecosystem functioning in European forests. J Appl Ecol. 2019;56:733-44. https://doi.org/10.1111/1365-2664.13308.

135. Manning P, van der Plas F, Soliveres S, Allan E, Maestre FT, Mace $\mathrm{G}$, et al. Redefining ecosystem multifunctionality. Nat Ecol Evol. 2018;2:427-36. https://doi.org/10.1038/s41559-0170461-7.

136. Koricheva J, Vehviläinen H, Riihimäki J, Ruohomäki K, Kaitaniemi P, Ranta H. Diversification of tree stands as a means to manage pests and diseases in boreal forests: myth or reality? Can J For Res. 2006;36:324-36. https://doi.org/10.1139/x05-172.

137. Ruohomäki K, Tanhuanpää M, Ayres MP, Kaitaniemi P, Tammaru T, Haukioja E. Causes of cyclicity of Epirrita autumnata (Lepidoptera, Geometridae): grandiose theory and tedious practice. Popul Ecol. 2000;42:211-23. https://doi.org/10. 1007/PL00012000.

138. Dwyer G, Dushoff J, Yee SH. The combined effects of pathogens and predators on insect outbreaks. Nature. 2004;430:341-5. https://doi.org/10.1038/nature02569.

139. Pureswaran DS, Johns R, Heard SB, Quiring D. Paradigms in eastern spruce budworm (Lepidoptera: Tortricidae) population ecology: a century of debate. Environ Entomol. 2016;46:133342. https://doi.org/10.1093/ee/nvw103.

140. Messier C, Puettmann KJ, Coates KD. Managing forests as complex adaptive systems: Abingdon-on-Thames: Routledge; 2013.

141. Seibold S, Bässler C, Baldrian P, Reinhard L, Thorn S, Ulyshen $\mathrm{MD}$, et al. Dead-wood addition promotes non-saproxylic epigeal arthropods but effects are mediated by canopy openness. Biol Conserv. 2016;204:181-8. https://doi.org/10.1016/j.biocon.2016. 09.031 .

142. Katano I, Doi H, Eriksson BK, Hillebrand H. A cross-system meta-analysis reveals coupled predation effects on prey biomass and diversity. Oikos. 2015;124:1427-35. https://doi.org/10.1111/ oik.02430.

143. Howe A, Lovei GL, Nachman G. Dummy caterpillars as a simple method to assess predation rates on invertebrates in a tropical agroecosystem. Entomol Exp Appl. 2009;131:325-9. https://doi. org/10.1111/j.1570-7458.2009.00860.x.

144. Rößler DC, Pröhl H, Lötters S. The future of clay model studies. BMC Zool. 2018;3:6. https://doi.org/10.1186/s40850-018-00336.

145. Brousseau P-M, Gravel D, Handa IT. Traits of litter-dwelling forest arthropod predators and detritivores covary spatially with traits of their resources. Ecology. 2019;100:e02815. https://doi.org/10. 1002/ecy.2815.

146. Bleicher SS. The landscape of fear conceptual framework: definition and review of current applications and misuses. PeerJ. 2017;5: e3772. https://doi.org/10.7717/peerj.3772.

147. Bucher R, Menzel F, Entling MH. Risk of spider predation alters food web structure and reduces local herbivory in the field. Oecologia. 2015;178:571-7. https://doi.org/10.1007/s00442-0153226-5.

148. Offenberg J, Damgaard C. Ants suppressing plant pathogens: a review. Oikos. 2019;128:1691-703. https://doi.org/10.1111/oik. 06744. 
149. Stork NE, Grimbacher PS. Beetle assemblages from an Australian tropical rainforest show that the canopy and the ground strata contribute equally to biodiversity. Proc R Soc B. 2006;273: 1969-75. https://doi.org/10.1098/rspb.2006.3521.

150. Floren A, Wetzel W, Staab M. The contribution of canopy species to overall ant diversity (Hymenoptera: Formicidae) in temperate and tropical ecosystems. Myrmecol News. 2014;19:65-74.

151. Schuldt A, Bruelheide H, Buscot F, Assmann T, Erfmeier A, Klein $\mathrm{AM}$, et al. Belowground top-down and aboveground bottom-up effects structure multitrophic community relationships in a biodiverse forest. Sci Rep. 2017;7:4222. https://doi.org/10.1038/ s41598-017-04619-3.

152. Poeydebat C, Tixier P, Chabrier C, de Bellaire LL, Vargas R, Daribo M-O, et al. Does plant richness alter multitrophic soil food web and promote plant-parasitic nematode regulation in banana agroecosystems? Appl Soil Ecol. 2017;117:137-46. https://doi. org/10.1016/j.apsoil.2017.04.017.

153. Klapwijk MJ. The effect of multiple natural enemies on a shared herbivore prey. Ecol Evol. 2019;9:9052-60. https://doi.org/10. 1002/ece3.5451.
154. Nixon AE, Roland J. Generalist predation on forest tent caterpillar varies with forest stand composition: an experimental study across multiple life stages. Ecol Entomol. 2012;37:13-23. https://doi.org/ 10.1111/j.1365-2311.2011.01330.x.

155. Griffiths HM, Ashton LA, Walker AE, Hasan F, Evans TA, Eggleton P, et al. Ants are the major agents of resource removal from tropical rainforests. J Anim Ecol. 2018;87:293-300. https:// doi.org/10.1111/1365-2656.12728.

156. Mottl O, Yombai J, Fayle TM, Novotny V, Klimes P. Experiments with artificial nests provide evidence for ant community stratification and nest site limitation in a tropical forest. Biotropica. 2020;52:277-87. https://doi.org/10.1111/btp.12684.

157. Staab M, Pufal G, Tscharntke T, Klein AM. Trap nests for bees and wasps to analyse trophic interactions in changing environments - a systematic overview and user guide. Methods Ecol Evol. 2018;9:2226-39. https://doi.org/10.1111/2041-210x.13070.

Publisher's Note Springer Nature remains neutral with regard to jurisdictional claims in published maps and institutional affiliations. 